\title{
An ATP-sensitive potassium channel blocker suppresses sodium-induced hypertension through increased secretion of urinary kallikrein
}

\author{
Yuji Kamata ${ }^{1,2}$, Tomoe Fujita ${ }^{2}$, Tetsuki Kato ${ }^{2}$, Izumi Hayashi ${ }^{3}$, Maya Kurosaka ${ }^{1,2}$, Makoto Katori ${ }^{2}$, \\ Yoshikuni Fujita ${ }^{1}$ and Masataka Majima ${ }^{2}$
}

It is suggested that an ATP-sensitive potassium channel blocker suppresses sodium-induced hypertension through increased secretion of urinary kallikrein. We reported that glibenclamide, an ATP-sensitive potassium channel blocker, accelerated dose-dependent secretion of renal kallikrein in sliced kidney cortex and in vivo in rats. In vehicle-treated normal BrownNorway-Kitasato (nBN-Ki) rats, the administration of glibenclamide increased urinary kallikrein secretion, but changed neither the systolic blood pressure nor the urinary sodium on low $(0.3 \%) \mathrm{NaCl}$ diets. Although on high $(8 \%) \mathrm{NaCl}$ diets, the systolic blood pressure of the nBN-Ki rats administrated glibenclamide was significantly lower $(P<0.05)$. The urinary levels of kallikrein and sodium of the $\mathrm{nBN}-\mathrm{Ki}$ rats administrated glibenclamide were significantly increased $(\boldsymbol{P}<0.05$, glibenclamide vs. vehicle). A similar result was obtained with a kidney-selective ATP-sensitive potassium blocker, N, $\mathrm{N}^{\prime}$-dicyclohexyl-4morpholinecarboxamidine (U18177), in SD rats. Mutant kininogen-deficient Brown-Norway Katholiek (muBN-Ka) rats fed high $(8 \%) \mathrm{NaCl}$ diets showed an increase in urinary kallikrein levels, but showed neither hypotensive nor natriuretic actions by glibenclamide. A bradykinin $\mathrm{B}_{2}$ receptor antagonist, 8-[3-[ $\mathrm{N}$-(E)-3-(6-acetamidopyridin-3-yl) acryloylglyycyl]- $\mathrm{N}$-methylamino]2,6-dichlorobenzyloxy]-2-methylquinoline (FR173657), which was administrated to SD rats, together with glibenclamide, abolished the hypotensive and natriuretic effects of glibenclamide in high-sodium $(8 \% \mathrm{NaCl})$ hypertension, despite an accelerated secretion of urinary kallikrein. Therefore, these results indicate that glibenclamide, an ATP-sensitive potassium channel blocker suppressed sodium-induced hypertension through sodium excretion from the kidney resulting from accelerated secretion of urinary kallikrein.

Hypertension Research (2009) 32, 220-226; doi:10.1038/hr.2008.33

Keywords: ATP-sensitive potassium channel blocker (glibenclamide); sodium-induced hypertension; renal kallikrein secretion

\section{INTRODUCTION}

In the early 1970s, it was reported that patients with essential hypertension excrete less urinary kallikrein than do normal healthy participants. ${ }^{1-3}$ Kallikrein is the enzyme responsible for the generation of kinins, kallidin and bradykinin from the precursor protein, kininogen. Bradykinin is well known to induce vasodilation, increase renal blood flow and excrete water and sodium from the kidney. ${ }^{1}$ It was recently revealed that the renal kallikrein-kinin system plays an important role in the localization of the kidney. The components of the tissue kallikrein-kinin system are localized along the distal nephron. ${ }^{4,5}$ After the tubulo-glomerular feedback system completes its role at the distal, connecting tubule cells secrete renal kallikrein, whereas the adjacent collecting tubule cells secrete kininogen. ${ }^{4}$ Bradykinin $B_{2}$ receptors are located along the cortical and medullary collecting ducts, which are downstream to the connecting tubules. ${ }^{5-8}$
Mutant Brown-Norway-Katholiek (muBN-Ka) rats are capable of producing kininogens in the liver, but cannot release them into the bloodstream, because of the point mutation of Ala163 to Thr in the structure of kininogen. ${ }^{9}$ Consequently, muBN-Ka rats excreted a much smaller amount of kinin in the urine than did normal rats of the same strain. ${ }^{10}$ In these experiments, muBN-Ka rats were compared with normal Brown-Norway Kitasato (nBN-Ki) rats, which are normal rats of the same original strain. BN-Ka rats fed a low $(0.3 \%) \mathrm{NaCl}$ diet showed neither physiological disorders nor a rise in systolic blood pressure (SBP). ${ }^{11}$ However, a diet containing $2 \%$ $\mathrm{NaCl}$ increased SBP to approximately $170 \mathrm{~mm} \mathrm{Hg}$ in muBN-Ka rats, but did not affect it in nBN-Ki rats. ${ }^{10}$ In addition, it was observed that sodium accumulated particularly in cells, such as erythrocytes and in body fluids, such as the cerebrospinal fluid, in muBN-Ka rats. ${ }^{10,12}$ It is important that sodium accumulation in the cells caused a 10-fold and

${ }^{1}$ Department of Endocrinology, Diabetes and Metabolism, Kitasato University, School of Medicine, Sagamihara, Kanagawa, Japan; 2 Department of Pharmacology, Kitasato University School of Medicine, Sagamihara, Kanagawa, Japan and ${ }^{3}$ Department of Pathophysiology, Nippon Pharmaceutical University, Ina, Saitama, Japan Correspondence: Dr M Majima, Department of Pharmacology, Kitasato University School of Medicine, Kitasato 1-15-1, Sagamihara, Kanagawa 228-8555, Japan. E-mail: mmajima@med.kitasato-u.ac.jp

Received 23 July 2008; revised 11 December 2008; accepted 29 December 2008 
a 30-fold increase in vascular sensitivity to angiotensin II and epinephrine, respectively. ${ }^{13}$ Consequently, a dysfunction of the renal kallikrein-kinin system leads to salt sensitivity in rats.

The increased secretion of urinary kallikrein because of potassium has been reported in animals ${ }^{14-16}$ and in humans with hypertension. ${ }^{17}$ Indeed, using the sliced kidney cortex, we have shown that potassium chloride in the perfusate accelerates the secretion of kallikrein in a concentration-dependent manner. ${ }^{18}$ Moreover, immediately after intravenous infusion of potassium gluconate solution into anesthetized Sprague-Dawley (SD) rats, urinary kallikrein secretion was accelerated with diuresis and natriuresis. ${ }^{19,20}$ Glibenclamide, an ATP-sensitive potassium channel blocker, is known to release insulin from the $\beta$ cell in the pancreas and is used for treatment of diabetes mellitus. It was reported that glibenclamide inhibited the transporter of $\mathrm{Na}^{+}$and $\mathrm{K}^{+}$in the ascending thick limb of Henle's loop by blocking $\mathrm{K}^{+}$recycling across the apical membrane. ${ }^{21}$ In addition, inhibition of $\mathrm{K}^{+}$secretion in the collecting tubules occurred by decreasing the activity of apical $\mathrm{K}^{+}$channels preventing kaliuresis. ${ }^{21}$ A kidneyselective ATP-sensitive potassium channel blocker, U18177 and its 1-adamantyl analog (U37883A) were developed as diuretics and as more selective blockers of the kidney ATP-sensitive channel. ${ }^{22,23}$ Glibenclamide and U37883A also dose-dependently accelerated the secretion of kallikrein from the kidney. ${ }^{18-20}$ A bradykinin $B_{2}$ receptor antagonist, FR173657, decreased the secretion of bradykinin and natriuresis. ${ }^{15}$ Therefore, diuresis and natriuresis induced by potassium or an ATP-sensitive potassium channel blocker may be mediated by the same mechanism of activation of the renal kallikrein-kinin system.

This study examined whether the sodium-induced rise of blood pressure is suppressed by the administration of either glibenclamide or U18177, through accelerated release of urinary kallikrein, and whether this effect is removed by FR173657.

\section{METHODS}

Mutant kininogen-deficient BN-Ka (muBN-Ka) rats and normal BN-Ki (nBN-Ki) rats, and male SD strain rats (specific pathogen-free, 6 weeks old from the Shizuoka Laboratory Animal Center in Hamamatsu) were used. All rats were given normal rat chow containing $0.3 \%$ sodium (NMF, Oriental Yeast Coap., Tokyo, Japan). They were housed at constant humidity $(60 \pm 5 \%)$ and temperature $\left(25 \pm 1{ }^{\circ} \mathrm{C}\right)$, and were kept on a continuous 12-h light-dark cycle. This study was performed in accordance with the Kitasato University School of Medicine guidelines for animal experiments.

The following drugs were used: glibenclamide (Sigma Chemical Co., St Louis, MO, USA), U18177 (a kidney-selective ATP-sensitive potassium blocker, Sigma-Aldrich Inc.) and FR173657 (a bradykinin B2 receptor antagonist, kindly provided by Fujisawa Pharmaceutical Co. Ltd., Osaka, Japan). We have reported earlier that glibenclamide accelerated dose-dependent secretion of renal kallikrein, in vivo, in rats and glibenclamide of $30 \mathrm{mg} / \mathrm{kg}$ also acted more strongly. ${ }^{19}$ Therefore, we administrated glibenclamide of $60 \mathrm{mg} / \mathrm{kg} /$ day $(30 \mathrm{mg} / \mathrm{kg}$, two times a day).

\section{Induction of hypertension}

Salt-induced hypertension: muBN-Ka, $\mathrm{nBN}-\mathrm{Ki}$ and SD rats were fed a diet to which was added $8 \% \mathrm{NaCl}$ and were provided distilled water during experimental periods.

\section{Measurement of systolic blood pressure}

Systolic blood pressure of unanesthetized rats was determined with tail-cuff plethysmography (model BP-98A, Softron, Tokyo, Japan), as reported previously. ${ }^{10}$

\section{Blood collection}

Blood was collected from the carotid artery of each strain from rats under light ether anesthesia, at day 8 of the experimental periods, as reported previously. ${ }^{10}$
For the determination of the sodium concentration of erythrocytes, blood was collected directly into tubes containing ice-chilled isosmotic lithium chloride solutions.

\section{Collection of urine and measurement of urinary creatinine and sodium}

Twenty-four-hour urine samples from individual rats during the experimental periods were collected in metabolic cages. Urine volume was recorded at the end of the 24-h period. Urinary creatinine was measured by a kinetic method using Jaffe's reaction. ${ }^{24}$ Urinary sodium was determined by using ion-selective electrodes (Fuji Dri-Chem Slide Na-K-Cl, Fuji Dri-Chem 800V; Fuji Film Co. Ltd., Tokyo, Japan).

\section{Measurement of urinary active kallikrein}

Activity of the active kallikrein in urine collected in metabolic cages over $24 \mathrm{~h}$ was measured using a peptidyl fluorogenic substrate selective for the tissue kallikrein, Pro-Phe-Arg-methyl-coumarinylamide (Peptide Institute, Minoh, Osaka, Japan). ${ }^{11}$ After a 10-fold dilution of the original urine with $0.2 \mathrm{moll}^{-1}$ of the Tris-HCl buffer ( $\mathrm{pH} 7.8$ ), $10 \mu \mathrm{l}$ of the diluted urine was incubated with $1 \mathrm{ml}$ of a $5 \times 10^{-5} \mathrm{moll}^{-1}$ of substrate solution in $0.05 \mathrm{moll}^{-1}$ of the Tris- $\mathrm{HCl}$ buffer containing $0.1 \mathrm{moll}^{-1}$ of $\mathrm{NaCl}$ and $0.01 \mathrm{moll}^{-1}$ of $\mathrm{CaCl}_{2}$ (pH 8.0). One arbitrary unit (AU) was defined as $1 \times 10^{-10} \mathrm{~mol}$ of the Tris- $\mathrm{HCl}$ buffer containing $0.1 \mathrm{moll}^{-1}$ of $\mathrm{NaCl}$ and $0.01 \mathrm{moll}^{-1}$ of $\mathrm{CaCl}_{2}(\mathrm{pH}$ 8.0). One $\mathrm{AU}$ was defined as $1 \times 10^{-10} \mathrm{~mol}$ of 7 -amino-4-methylcoumarin for $10 \mathrm{~min}$ per microliter of urine at $37{ }^{\circ} \mathrm{C} .{ }^{10}$ The activity was termed as that which divided the active kallikrein by creatinine $(\mathrm{Cr})$.

\section{Measurement of erythrocyte sodium concentration}

Erythrocyte from the carotid artery was washed three times with an isotonic lithium chloride solution. The pellets of the obtained erythrocyte were lysated with distilled water, and the resulting sample was diluted with $0.5 \mathrm{~N}$ of $\mathrm{HNO}_{3}$. Intracellular sodium concentrations of erythrocyte (RBC[Na]i) were determined with plasma optical emission spectrometer (SPS-7700, Seiko Instruments Inc., Chiba, Japan). The results were expressed as $\mathrm{mmoll}^{-1}$ red blood cell (RBC).

\section{Measurement of intracellular sodium concentrations of vascular tissues}

Measurement of intracellular sodium concentrations of vascular tissues (vascular $[\mathrm{Na}] \mathrm{i}$ ) was performed using abdominal aorta. The abdominal aorta was isolated and the connective tissues around the aorta were carefully removed. The vascular tissues were homogenized with distilled water ( $1 \mathrm{ml}$ for $100 \mathrm{mg}$ of wet tissue of aorta) with polytrone. The sodium concentrations in the supernatant of the homogenates were determined with the above-mentioned plasma optical emission spectrometer. The results were expressed as $\mathrm{mmol} \mathrm{kg}-1$ of wet tissue.

\section{Measurement of blood glucose}

Blood glucose was measured by enzymatic colorimetry using D-glucose oxidase (Medisefu-Mini, Terumo corp., Tokyo, Japan). This method used arterial blood of about $1.2 \mu \mathrm{l}$ at any time till the end of the experiment.

\section{Statistical analysis}

Values are expressed as mean \pm s.e.m. One-way ANOVA or Student's $t$-test or post hoc Dunnet's test was used to evaluate the statistical significance of the difference. Differences with a probability of $5 \%$ or less were considered to be significant.

\section{RESULTS}

Normal BN-Ki rats, which continued a diet containing $0.3 \%$ of $\mathrm{NaCl}$ for 5 days, did not show a rise of SBP on day $5(112 \pm 3 \mathrm{~mm} \mathrm{Hg}, n=6)$. Administration of glibenclamide $\left(30 \mathrm{mg} \mathrm{kg}^{-1}\right.$, p.o., two times a day) significantly increased the secretion of urinary kallikrein to $8.5 \pm 1.0 \mathrm{AU} \mathrm{mg}^{-1} \mathrm{Cr}$ compared with $3.9 \pm 0.5 \mathrm{AUmg}^{-1} \mathrm{Cr}$ in 


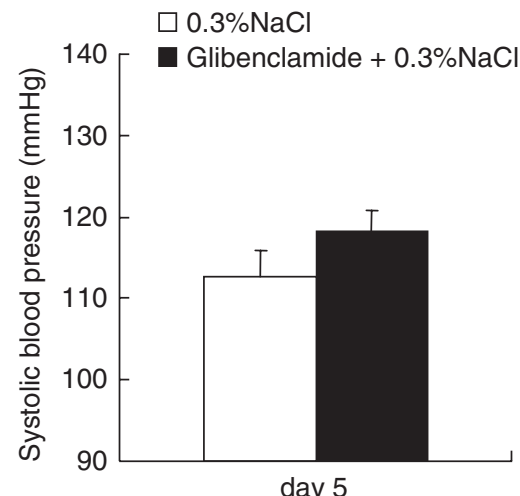

day 5

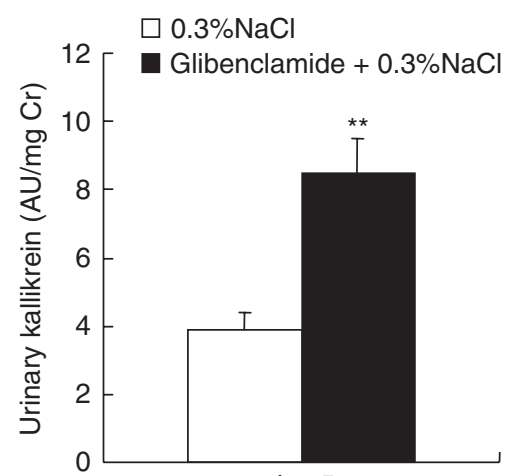

day 5

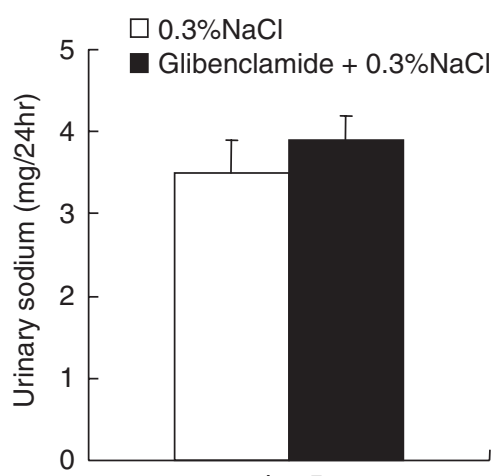

day 5

Figure 1 Systolic blood pressure (SBP), urinary kallikrein and urinary sodium in normal Brown Norway (nBN-Ki) rats fed $0.3 \% \mathrm{NaCl}$ diet. Open columns are a vehicle group. Glibenclamide $\left(60 \mathrm{mg} \mathrm{kg}^{-1}\right)$ was administered to rats throughout the experiment period. Values are mean \pm s.e.m., $n=6$. ${ }^{* *} P<0.01$ vs. value in the vehicle control group.
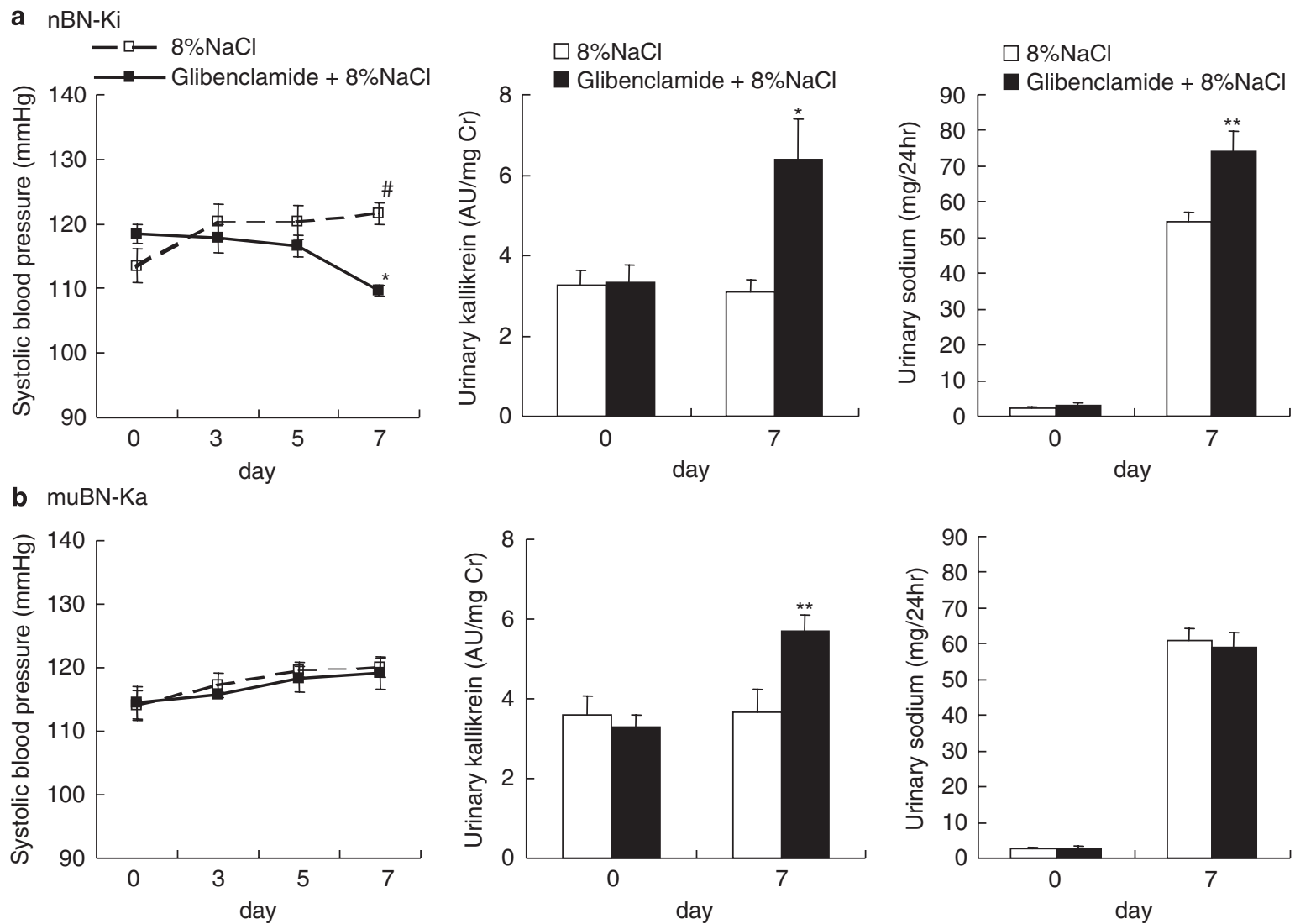

Figure 2 Line and columns show results of systolic blood pressure (SBP), urinary kallikrein and urinary sodium in normal Brown Norway-Kitasato (nBN-Ki) rats (a) and mutant Brown Norway Katholiek (muBN-Ka) rats (b) fed an $8 \% \mathrm{NaCl}$ diet. Straight line and open columns represent the vehicle control group. Broken line and closed columns represent the glibenclamide-treated group $\left(60 \mathrm{mg} \mathrm{kg}^{-1}\right)$. Blood pressure was measured on days $0,3,5$ and 7 . Urinary kallikrein and urinary sodium were measured on days 0 and 7 . Values are mean \pm s.e.m., $n=6 .{ }^{\#} P<0.05$ vs. SBP on day 0 in the vehicle control group. ${ }^{*} P<0.05,{ }^{*} P<0.01$ vs. value in the vehicle control group.

vehicle-treated rats (Figure 1). Neither SBP nor urinary sodium was changed by glibenclamide. In our earlier report, the SBP of normal BN-Ki rats that were fed a high $(8 \%) \mathrm{NaCl}$ diet, increased from $124 \pm 4 \mathrm{~mm} \mathrm{Hg}$ on day $0,146 \pm 1 \mathrm{~mm} \mathrm{Hg}$ on day 7 and to $163 \pm 3 \mathrm{~mm} \mathrm{Hg}$ on day $14 .{ }^{10}$ In this experiment, during 7 days, the SBP of normal BN-Ki rats increased from $113.5 \pm 2.6$ to $122 \pm 2 \mathrm{~mm} \mathrm{Hg}$ under an $8 \% \mathrm{NaCl}$ diet, whereas the SBP of rats that were administrated glibenclamide fell to $110 \pm 1 \mathrm{~mm} \mathrm{Hg}$ on day 7 (Figure 2a). Urinary kallikrein on day 7 increased to $6.4 \pm 1.0 \mathrm{AU} \mathrm{mg}^{-1}$ $\mathrm{Cr}$, compared with $3.4 \pm 0.3 \mathrm{AU} \mathrm{mg}^{-1} \mathrm{Cr}$ in vehicle-treated rats. Urinary sodium excretion increased in vehicle-treated rats from $2.4 \pm 0.4 \mathrm{mg} / 24 \mathrm{~h}$ on day 0 and $54.3 \pm 2.9 \mathrm{mg} / 24 \mathrm{~h}$ on day 7 , but increased to $74.0 \pm 7.3 \mathrm{mg} / 24 \mathrm{~h}$ on day 7 in rats administered with glibenclamide. 

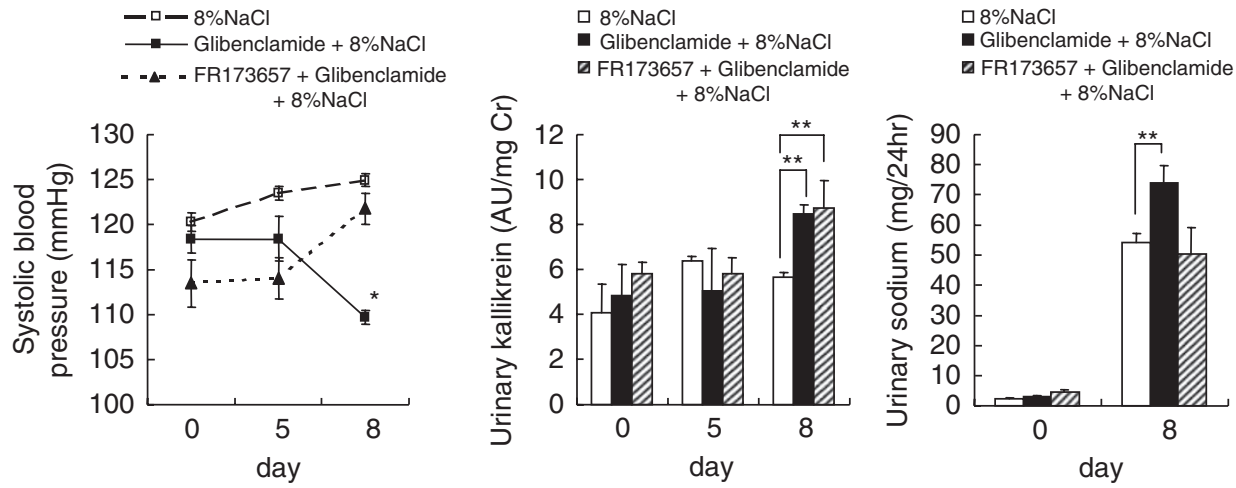

Figure 3 Systolic blood pressure (SBP), urinary kallikrein and urinary sodium in Sprague-Dawley strain (SD) rats fed an $8 \% \mathrm{NaCl}$ diet. A bradykinin $\mathrm{B}_{2}$ receptor antagonist (FR173657) was given to rats at a doze of $100 \mathrm{mg} / \mathrm{kg}$. Blood pressure, urinary kallikrein and urinary sodium were measured on days 0 , 5 and 8 . Values are mean \pm s.e.m., $n=6$. ${ }^{*} P<0.05,{ }^{*} P<0.01$ vs. value on same days in the vehicle control group.
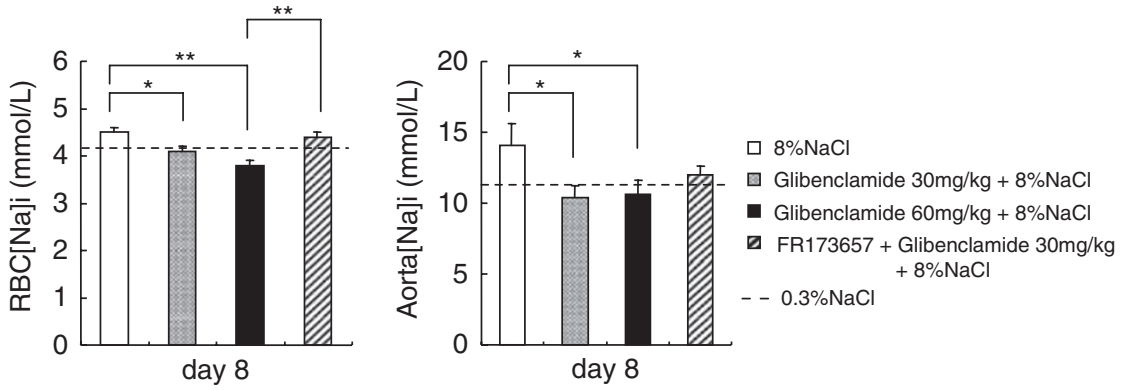

Figure 4 Columns show results of intracellular sodium concentration of erythrocyte (RBC[Na]i) and aorta in SD rats fed an $8 \% \mathrm{NaCl}$ diet on day 8 . Broken line shows the mean intracellular sodium concentration in SD rats fed a $0.3 \% \mathrm{NaCl}$ diet on day 8 . Values are mean \pm s.e.m., $n=6-10$. ${ }^{*} P<0.05$, ${ }^{* *} P<0.01$ vs. value in the vehicle-treated group.

Kininogen-deficient $\mathrm{BN}-\mathrm{Ka}$ rats that were fed an $8 \% \mathrm{NaCl}$ diet, also raised SBP $(120 \pm 2 \mathrm{~mm} \mathrm{Hg})$ and increased urinary sodium $(61 \pm 3 \mathrm{mg} / 24 \mathrm{~h}$ ) on day 7 (Figure $2 \mathrm{~b}$ ). Glibenclamide did not inhibit the rise of SBP and the increase in urinary sodium excretion on day 7 , although urinary kallikrein increased significantly to $5.7 \pm 0.4 \mathrm{AU} / \mathrm{mg} \mathrm{Cr}$.

In SD strain rats that were fed an $8 \% \mathrm{NaCl}$ diet, suppression of SBP rise by glibenclamide was ceased by the administration of a bradykinin $\mathrm{B}_{2}$ antagonist, FR173657 (100 $\mathrm{mg} \mathrm{kg}^{-1}$; p.o., two times a day) (Figure 3 ). The administration of glibenclamide significantly decreased SBP from $118 \pm 2 \mathrm{~mm} \mathrm{Hg}$ on day 0 to $110 \pm 1 \mathrm{~mm} \mathrm{Hg}$ on day 8. The administration of FR173657 did not decrease SBP. Nevertheless, urinary kallikrein was increased by glibenclamide, from $4.9 \pm 1.4 \mathrm{AU} / \mathrm{mg} \mathrm{Cr}$ on day 0 , to $8.5 \pm 0.4 \mathrm{AU} / \mathrm{mg} \mathrm{Cr}$ on day 8 and from $5.8 \pm 0.5 \mathrm{AU} / \mathrm{mg} \mathrm{Cr}$ on day 0 , to $8.7 \pm 1.2 \mathrm{AU} / \mathrm{mg} \mathrm{Cr}$ on day 8 . However, the increase in urinary sodium was only found in the solo administration of glibenclamide. These results indicated that the effects of glibenclamide on the blood pressure and urinary sodium were abolished by FR173657.

When intracellular sodium concentrations were determined, SD strain rats that were fed an $8 \% \mathrm{NaCl}$ diet increased in $\mathrm{RBC}[\mathrm{Na}] \mathrm{i}$ compared with SD strain rats that were fed a $0.3 \%$ $\mathrm{NaCl}$ diet (Figure 4, left panel, $0.3 \% \mathrm{NaCl}: 4.1 \pm 0.4 \mathrm{mmoll}^{-1}, 8 \%$ $\left.\mathrm{NaCl}: 4.5 \pm 0.4 \mathrm{mmoll}^{-1}\right)$. In addition, sodium concentrations of vascular smooth muscles in the aorta showed similar results (Figure 4, right panel, $\quad 0.3 \% \quad \mathrm{NaCl}: 11.4 \pm 0.7 \mathrm{mmoll}^{-1}, \quad 8 \% \quad \mathrm{NaCl}: 14.1 \pm$ $\left.1.5 \mathrm{mmoll}^{-1}\right)$. Meanwhile, gibenclamide dose-dependently reduced $\mathrm{RBC}[\mathrm{Na}] \mathrm{i}$, which were elevated by an $8 \%$ high-sodium diet
(Figure 4, left panel, $30 \mathrm{mg} \mathrm{day}^{-1}: 4.1 \pm 0.1 \mathrm{mmoll}^{-1}, 60 \mathrm{mg} \mathrm{day}^{-1}$ : $\left.3.8 \pm 0.1 \mathrm{mmoll}^{-1}\right)$. The effect of $60 \mathrm{mg} \mathrm{kg}^{-1}$ of glibenclamide was removed by the simultaneous administration of FR173657 (Figure 4, left panel). The same result was obtained in the aorta. Glibenclamide reduced the intracellular sodium concentration of the vascular smooth muscle, which was elevated by an $8 \%$ high-sodium diet (Figure 4 , right panel, $30 \mathrm{mg} \mathrm{day}^{-1}: 10.4 \pm 0.8 \mathrm{mmoll}^{-1}, \quad 60 \mathrm{mg} \mathrm{day}^{-1}: 10.6 \pm$ $\left.1.0 \mathrm{mmoll}^{-1}\right)$. The effect of $30 \mathrm{mg} \mathrm{kg}^{-1}$ of glibenclamide was also removed by the simultaneous administration of FR173657 (Figure 4, right panel).

A kidney-selective ATP-sensitive potassium blocker, U18177, also significantly suppressed the rise of SBP in the SD strain rats that were fed an $8 \% \mathrm{NaCl}$ diet $(122 \pm 2 \mathrm{~mm} \mathrm{Hg}$ on day 4$)$ in comparison with vehicle rats $(112 \pm 1 \mathrm{~mm} \mathrm{Hg}$ ) (Figure 5). Moreover, urinary sodium excretion $(84.5 \pm 7.3 \mathrm{mg} / 24 \mathrm{~h}$ on day 5$)$ was increased through the markedly accelerated secretion of urinary kallikrein $(7.1 \pm 0.3 \mathrm{AU} / \mathrm{mg}$ Cr on day 4).

No rat died during the experiments, in spite of the use of a sufficient dose of glibenclamide. The blood glucose levels by the end of the experiment (day 8) were reduced slightly, but dose dependently, with glibenclamide $\left(0.3 \% \mathrm{NaCl}\right.$ : $177 \pm 13 \mathrm{mg}$ per $100 \mathrm{ml}^{-1}, 8 \% \mathrm{NaCl}$ : $181 \pm 6 \mathrm{mg}$ per $100 \mathrm{ml}^{-1}$, glibenclamide $30 \mathrm{mg} \mathrm{day}^{-1}: 169 \pm 4 \mathrm{mg}$ per $100 \mathrm{ml}^{-1}$, glibenclamide $60 \mathrm{mg} \mathrm{day}^{-1}: 160 \pm 8 \mathrm{mg}$ per $100 \mathrm{ml}^{-1}$ ).

\section{DISCUSSION}

The importance of dietary sodium chloride in the regulation of blood pressure has received much attention over the past few years, but this area of research and knowledge is still being debated. ${ }^{25}$ We have 

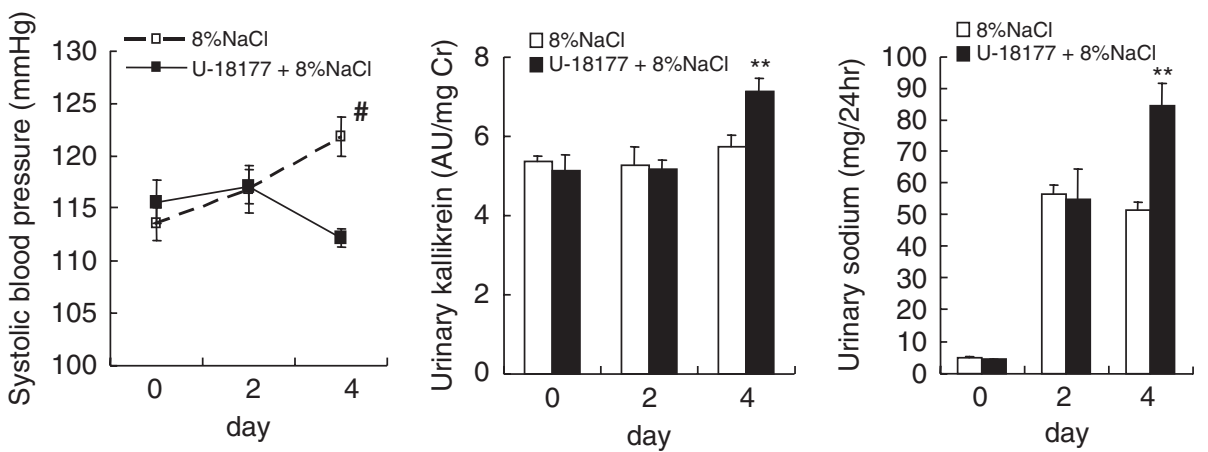

Figure 5 Systolic blood pressure (SBP), urinary kallikrein and urinary sodium in Sprague-Dawley strain (SD) rats fed an $8 \% \mathrm{NaCl}$ diet. A kidney-selective ATP-sensitive potassium blocker (U-18177) was given to rats $\left(60 \mathrm{mg} \mathrm{kg}^{-1}\right)$. Blood pressure, urinary kallikrein and urinary sodium were measured on days 0 , 2 and 4. Values are mean \pm s.e.m., $n=6$. ${ }^{\#} P<0.05$ vs. SBP on day 0 in the vehicle control group. ${ }^{*} P<0.01$ vs. value on same days in the vehicle control group.

reported earlier that high sodium loading, which included more than a $4 \% \mathrm{NaCl}$ diet, raised the SBP of normal dosage-dependent $\mathrm{BN}-\mathrm{Ki}$ rats, whereas in contrast, mutant kininogen-deficient $\mathrm{BN}-\mathrm{Ka}$ rats were sensitive to sodium, so that a loading of $2 \% \mathrm{NaCl}$ diet raised SBP. In brief, we infer that the SBP is increased by the relation between the dysfunction of the renal kallikrein-kinin system and sodium loading.

Initially, we confirmed that the administration of glibenclamide accelerated the secretion of urinary kallikrein and thereby changed SBP and urinary sodium. The accelerated secretion of urinary kallikrein was not tied to the increase of sodium excretion or to the suppression of SBP rise as long as the rats were put on a normal $0.3 \%$ of $\mathrm{NaCl}$ diet (Figure 1). On the other hand, it showed the rise of SBP and increase in urinary sodium excretion with the secretion of urinary kallikrein, when the same rats were put on loading of a high $8 \% \mathrm{NaCl}$ diet (Figure 2a). Increased kallikrein secretion might stimulate sodium excretion through kinin formation, which was judged from the effect of a $B_{2}$ antagonist on urinary sodium excretion treated with an ATP-sensitive potassium blocker.

Further, we confirmed whether the natriuretic actions and the suppression of SBP rise appeared by the administration of glibenclamide in the presence of the dysfunction of the renal kallikrein-kinin system. In mutant kininogen-deficient BN-Ka rats, glibenclamide had no effect on the suppression of SBP rise and the increase in urinary sodium excretion (Figure 2b). Similarly, when FR173657 was administrated simultaneously with glibenclamide, the suppression of SBP rise and the increase in urinary sodium excretion did not occur, although urinary kallikrein increased (Figure 3). These results showed that the natriuretic actions and the suppression of SBP rise did not appear unless the kallikrein-kinin system functioned normally under high sodium intake, even if glibenclamide increased the secretion of kallikrein. In other words, the natriuretic actions and thereby the suppression of the SBP rise occurred by the action of kallikrein, and its secretion increased by glibenclamide.

The measurement of intracellular sodium concentrations not only in RBC but also in vascular smooth muscles revealed that the high sodium intake resulted in the accumulation of sodium in the cells. Glibenclamide administration really canceled the accumulation of sodium possibly through increased secretion of kallikrein (Figure 4). This was confirmed by a bradykinin $\mathrm{B}_{2}$ antagonist administration, the receptor signaling of which was reported to increase renal sodium excretion (Figure 4). However, there was no significant difference in the intracellular concentrations of vascular smooth muscles between glibenclamide administration and bradykinin $\mathrm{B}_{2}$ antagonist adminis- tration. $\mathrm{RBC}[\mathrm{Na}] \mathrm{i}$ has been used for many studies of hypertension, because RBC is a specimen that can easily be obtained and has the lowest quantity of $\mathrm{Na}^{+} / \mathrm{K}^{+}$ATPase activity in per tissue weight. ${ }^{26}$ Meanwhile, in vascular smooth muscles, isolation of the abdominal aorta needs a close technique. Furthermore, the reduction of $\mathrm{Na}^{+} / \mathrm{Ca}^{2+}$ exchanger activity, the increase of $\mathrm{Na}^{+}$influx and $\mathrm{Na}^{+} / \mathrm{K}^{+}$ATPase activity have been reported in experimental hypertension with a high salt diet. ${ }^{27-29}$ We think that these different results were obtained with $\mathrm{RBC}$ and vascular smooth muscles because of the influence of various factors. It is plausible that increased accumulation of sodium in smooth muscles may become sensitive to the evaluation of vasoconstricting substances through increased mobilization of calcium from the intracellular store sites.

In this experiment, we evaluated natriuretic actions and the suppression of SBP rise using another ATP-sensitive potassium blocker, U18177 (Figure 5). Nevertheless, the period of administration with U18177 was brief as opposed to glibenclamide, natriuretic actions and the suppression of the SBP rise were observed. We could speculate that this effect of U18177 appeared more rapidly than that of glibenclamide, because U18177 was an ATP-sensitive potassium channel blocker of a selective kidney.

Collectively, it was suggested that glibenclamide, an ATP-sensitive potassium channel blocker, suppressed sodium-induced hypertension through the increased secretion of urinary kallikrein. We reviewed the kind of results that would be obtained, whether a similar experiment was carried out on Dahl salt-sensitive rats. There are no experimental reports that used glibenclamide in Dahl salt-sensitive rats. Instead, it was known that urinary kallikrein decreased in Dahl salt-sensitive rats. $^{30}$ Therefore, glibenclamide would suppress sodium-induced hypertension through the increased secretion of urinary kallikrein in Dahl salt-sensitive rats. We suggested that kallikrein played a large role as a mechanism of hypertension by a natriuretic fine adjustment in the kidney.

It was difficult to explain the mechanisms of glibenclamide on the secretion of renal kallikrein at the cellular level of the connecting tubule. When a high sodium diet was given to rats, the sodium excreted from the glomerulus was markedly increased in spite of increased reabsorptions in the proximal tubules and other segments of the nephrones. It was known that more than $90 \%$ of sodium secreted from the glomerulus was reabsorbed by the portions of nephrones situated before the collecting ducts. Kallikrein was secreted mainly from the connecting ducts that were located before the collecting ducts where $\mathrm{B} 2$ receptors were present. The functional relevance of urinary 
kallikrein to sodium handling was restricted to the collecting ducts because of the localization of the components of the renal kallikrein systems. We recognized the increase in excretion of sodium under high sodium diets even when the urinary kallikrein secretion was unchanged in normal rats as well as in kininogen-deficient rats (Figure 2). But, as shown in Figures 2a and 3, the urinary kallikrein that was increased by glibenclamide by $50-100 \%$ was active in terms of the increased excretion of sodium. The segment of the collecting ducts was the final portion where sodium handling could be adjusted. As shown here, we would like to show the activity of the renal kallikreinkinin system to enhance sodium excretion. Glibenclamide inhibited the transport of $\mathrm{Na}^{+}$and $\mathrm{K}^{+}$in the ascending thick limb of Henle's loop by blocking $\mathrm{K}^{+}$recycling across the apical membrane. ${ }^{21}$ This inhibition led to the delivery of the large amounts of fluid and $\mathrm{Na}^{+}$at the initial and cortical collecting tubule. ${ }^{31}$ This action was similar to a loop diuretic such as furosemide. Moreover, the secretion of $\mathrm{K}^{+}$was stimulated with increased luminal pressure at the distal tubule flow dependently. In fact, the maxi $\mathrm{K}^{+}$channel, besides the ATP-sensitive potassium channel in the apical membrane, was responsible for the flow-dependent $\mathrm{K}^{+}$secretion by coupling with the stretch-activated cation channel in the connecting tubule of the rabbit. ${ }^{32}$ On the other hand, kaliuresis was not caused by glibenclamide, because its control depended on the initial and cortical collecting tubules. ${ }^{33}$ We could speculate that this increased $\mathrm{K}^{+}$in the lumen led to the inhibition of the ATP-sensitive potassium channel and depolarization of the cell of the connecting tubules. Therefore, these results suggested that the inhibition of the ATP-sensitive potassium channel by glibenclamide might increase the secretion of renal kallikrein.

It is possible that the secretion of renal kallikrein was explained by the calcium influx. In the experiment using dissected renal-connecting tubule of SD rats, we reported that potassium-induced secretion of renal kallikrein was inhibited by disodium-ethylendiamine-tetraacerate dihydrate (EDTA-2Na) and by $\mathrm{NiCl}_{2} \cdot{ }^{34}$ In addition, an L-type calcium channel blocker, verapamil, slightly inhibited the secretion of renal kallikrein. An $\mathrm{IP}_{3}$ receptor-selective antagonist, xestspongin $\mathrm{C}$ and a ryanodine-sensitive receptor blocker, ruthenium, also yielded the same results. The maxi $\mathrm{K}^{+}$channel on the apical membrane in the distal nephron with the epithelial calcium channel (ECaC) was inhibited by verapamil. ${ }^{32}$ These results showed that calcium influx through $\mathrm{ECaC}$ was necessary for the mobilization of the intracellular calcium store for the secretion of renal kallikrein. There was a possibility that the calcium influx was induced by the action through the $\mathrm{Na}^{+} / \mathrm{Ca}^{2+}$ exchanger on the vasolateral membrane, ${ }^{35}$ although this was not clarified in this study.

At present, however, we consider that the depolarization that resulted from increased calcium influx may accelerate the secretion of renal kallikrein because of the changes in the transport of electrolyte caused by glibenclamide-induced ATP-sensitive potassium channel blockade. More accurate knowledge of a mechanism by glibenclamide will be obtained by electrochemical studies using a dissected renalconnecting tubule cell.

We considered whether other effects of glibenclamide affected blood pressure and natriuresis. Glibenclamide releases insulin from the $\beta$ cell in the pancreas. Although insulin is generally known to have a hypoglycemic action, it produces various actions in metabolism. Insulin acted on the distal renal tubule to retain $\mathrm{Na}^{+}$and water. ${ }^{36}$ Insulin also stimulated the cell-membrane $\mathrm{Na}^{+} / \mathrm{K}^{+}$ATPase, which raised intracellular $\mathrm{Na}^{+}$concentrations in vascular smooth muscles and increased systolic $\mathrm{Ca}^{2+}$ levels, which enhanced contractility and increased peripheral resistance. ${ }^{37,38}$ On one hand, the main action of insulin is hypoglycemia. Through its effect on the central nervous system, sympathetic tension might be enhanced. No hypoglycemia was measured at any time during the experimental period. We could not confirm whether blood pressure was changed by hypoglycemia, because we did not measure blood glucose on any day. On the other hand, insulin was an endothelium-dependent vasodilator, releasing nitric oxide (NO) from the endothelium, which relaxes the vascular smooth muscle. ${ }^{39}$ Therefore, insulin released by glibenclamide might influence blood pressure and natriuresis partly.

In conclusion, this study pointed out the possibility that glibenclamide, an ATP-sensitive potassium channel blocker, activated the kallikrein-kinin system, caused diuretic and natriuretic action and finally declined systolic blood pressure. Although this study is an animal experiment under an unusually high salt diet, we suggest that it would lead to the development of a critical prevention of hypertension, if molecular mechanisms of the kallikrein-kinin system were elucidated in future.

\section{ACKNOWLEDGEMENTS}

We thank Fujisawa Pharmaceutical Co., Ltd., Osaka, Japan for providing the kidney FR173657 and Mrs M Ogino for her excellent technical assistance. This work was supported by the following grants: Research Grants (no. 15390084, no. 16022256, no. 16659067), a 'High-tech Research Center', The 21th Century COE program established by the Ministry of Education, Culture, Sports Science and Technology (MEXT) of Japan, the Integrative Research Program of the Graduate School of Medical Science Kitasato University and the Parents' Association Grant of Kitasato University School of Medicine.

\section{CONFLICT OF INTEREST}

The authors declare no conflict of interest.

1 Schneider EG, Strandhoy JW, Willis LR, Know FG. Relationship between proximal sodium reabsorption and excretion of calcium, magnesium and phosphate. Kidney Int 1973; 4: 369-376.

2 Margolius HS, Geller R, Pisano JJ, Sjoerdsma A. Altered urinary kallikrein excretion in human hypertension. Lancet 1971; 2: 1063-1065.

3 Margolius HS, Horwitz D, Pisano JJ, Keiser HR. Urinary kallikrein excretion in hypertensive man. Relationships to sodium intake and sodium-retaining steroids. Circ Res 1974; 35: 820-825.

4 Figueroa CD, Maciver AG, Mackenzie JC, Bhoola KD. Localization of immunoreactive kininogen and tissue kallikrein in the human nephron. Histochemistry 1988; 89: 437-442.

5 Katori M, Majima M. The renal kallikrein-kinin system:its role as a safety valve for excess sodium intake, and its attenuation as a possible etiologic factor in solt-sensitive hypertension. Crit Rev Clin Lab Sci 2003; 40: 43-115.

6 Figueroa CD, Gonzalez CB, Grigoriev S, Abd Alla SA, Haasemann M, Jarnagin K, MüllerEsterl W. Probing for the Bradykinin $B_{2}$ recepter in rat kidney by antipeptide and antiligand antibodies. J Histochem Cytochem 1995; 43: 137-148.

7 Kuribayashi Y, Majima M, Katori M. Major kininases in rat urine are neutral endopeptidase and carboxypeptidase Y-like exopeptidase. Biomed Res 1993; 14: 191-201.

8 Yang T, Terada Y, Nonoguchi H, Tsujino M, Tomita K, Marumo F. Distribution of kallikrein-binding protein mRNA in kidneys and difference between SHR and WKY rats. Am J Physiol 1994; 267: F325-F330.

9 Hayashi I, Hoshiko S, Manabe O, Oh-ishi S. A point mutation of Alanine163 to threonine is responsible for defective secretion of high molecular weight kininogen by the liver of Brown Norway Katholiek rats. J Biol Chem 1993; 268: 17219-17224.

10 Majima M, Yoshida O, Mihara H, Muto T, Mizogami S, Kuribayashi Y, Katori M, Oh-ishi S. High sensitivity to salt in kininogen-deficient Brown Norway Katholiek rats. Hypertension 1993; 22: 705-714.

11 Majima M, Katori M, Hanazuka M, Mizogami S, Nakano T, Nakao Y, Mikami R, Uryu H, Okamura R, Mohsin SS, Oh-ishi S. Suppression of rat deoxycorticosterone-salt hypertension by kallikrein-kinin system. Hypertension 1991; 17 (6 Part 1): 806-813.

12 Majima M, Mizogami S, Kuribayashi Y, Katori M, Oh-ishi S. Hypertension induced by a nonpressor dose of angiotensin II in kininogen-deficient rats. Hypertension 1994; 24: 111-119.

13 Majima M, Adachi K, Kuribayashi Y, Mizogami S, Katori M. Increase in vascular sensitivity to angiotensin II and epinephrine after four day infusion of $0.3 \mathrm{M}$ sodium chloride in conscious kininogen-deficient Brown Norway Katholiek rats. Jpn J Pharmacol 1995; 69: 149-158. 
14 Vio C, Figueroa C. Evidence for a stimulatory effect of high potassium diet on renal kallikrein. Kidney Int 1987; 31: 1327-1334.

15 Suzuki T, Katori M, Fujita T, Kumagai Y, Majima M. Involvement of the renal kallikreinkinin system in $\mathrm{K}^{+}$-induced diuresis and natriuresis in anesthetized rats. Eur $\mathrm{J}$ Pharmacol 2000; 399: 223-227.

16 Barden A, Beilin L, Vandongen R. Effect of potassium supplementation on blood pressure and vasodilator mechanisms in spontaneously hypertensive rats. Clin Sci 1988; 75: 527-534.

17 Murakami E, Hiwada K, Kokubu T, Imamura Y. Effect of oral potassium on urinary kallikrein excretion in essential hypertension. Adv Exp Med Biol 1989; 247B: 133-137.

18 Hayashi I, Fujita T, Majima M, Katori M. A secretory mechanism of renal kallikrein by a high potassium ion; a possible involvement of ATP-sensitive potassium channel. Immunopharmacology 1999; 44: 49-55.

19 Fujita T, Hayashi I, Kumagai Y, Inamura N, Majima M. Early increase in renal kallikrein secretion on administration of potassium or ATP-sensitive potassium channel blocker in rats. Br J Pharmacol 1999; 128: 1275-1283.

20 Fujita T, Hayashi I, Kumagai Y, Inamura N, Majima M. $\mathrm{K}^{+}$loading, but not $\mathrm{Na}^{+}$loading, and blockade of ATP-sensitive $\mathrm{K}+$ channels augment renal kallikrein secretion. Immunopharmacology 1999; 44: 169-175.

21 Wang T, Wang WH, Robbenharr G, Giebisch G. Effects of glyburide on renal tubule transport and potassium-channel activity. Ren Physiol Biochem 1995; 18: 169-182.

22 Perricone SC, Humphrey SJ, Skaletzky LL, Graham BE, Zandt RA, Zins GR. Synthesis and diuretic activity of alkyl- and arylguanidine analogs of $N, N^{\prime}$-dicyclohexyl-4morpholinecarboxamidine in rats and dogs. J Med Chem 1994; 37: 3693-3700.

23 Guillemare E, Honoroe E, De werlle J, Fosset M, Lazdundski M, Meisheri K. Functional receptors in Xenopus oocytes for U-37883A, a novel ATP-sensitive $\mathrm{K}+$ channel blocker: comparison with rat insulinoma cells. Mol Pharmacol 1994; 46: 139-145.

24 Fabiny D, Ertingshausen G. Automated reaction-rate method for the determination of serum creatinine with the Centrifichem. 1971; 17: 1224-1227.

25 Jones DW. Dietary sodium and blood pressure. Hypertension 2004; 43: 932-935.

26 Bonting SL, Caravaggio LL, Hawkins NM. Studies on sodium-potassium-activated adenosinetriphosphatase. IV. Correlation with cation transport sensitive to cardiac glycosides. Arch Biochem Biophys 1962; 98: 413-419.
27 Ashida T, Kawano Y, Yoshimi H, Kuramochi M, Omae T. Effects of dietary salt on sodium-calcium exchanger and ATP-driven calcium pump in arterial smooth muscles of Dahl rats. J Hypertens 1992; 10: 1335-1341.

28 Vasdev S, Prabhakaran V, Sampson CA. Elevated 22Na uptake in aortae of Dahl saltsensitive rats with high salt diet. Artery 1990; 17: 289-296.

29 Pamnani MB, Clough DL, Huot SJ, Haddy FJ. Vascular sodium-potassium pump activity in various models of experimental hypertension. Clin Sci (Lond) 1980; 59. 179-181.

30 Churchill PC, Churchill MC, Bidani AK, Rabito SF. Kallikrein excretion in Dahl saltsensitive and salt-resistant rats with native and transplanted kidneys. Am J Physiol 1995; 269: F710-F717.

31 Stanton B, Giebisch G. Renal potassium transport: mechanisms and regulation. Am J Physiol 1998; 274: F817-F833.

32 Muto S. Potassium transport in the mammalian collecting duct. Physiol Rev 2001; 81 : 85-116.

33 Taniguchi J, Imai M. Flow-dependent activation of maxi $\mathrm{K}^{+}$channels in apical membrane of rabbit connecting tubule. J Membr Biol 1998; 164: 35-45.

34 Wang T, Wang WH, Robbenharr G, Giebisch G. Effects of a novel KATP channel blocker on renal tubule function and K channel activity. J Pharmacol Exper Ther 1995; 273 : 1382-1389.

35 Yamanaka M, Hayashi I, Fujita T, Cha SH, Endou H, Higashihara M, Majima M. Potassium-induced increase in renal kallikrein secretion is attenuated in dissected renal connecting tubule of young spontaneously hypertensive rats. Int Pharmacol 2002; 2: 1957-1964.

36 DeFronzo RA, Goldberg M, Agus ZS. The effects of glucose and insulin on renal electrolyte transport. J Clin Invest 1976; 58: 83-90.

37 Hall JE, Summers RL, Brands MW, Keen H, Alonso-Galicia M. Resistance to metabolic actions of insulin and its role in hypertension. Am J Hypertens 1994; 7: 772-788.

38 Morris AD, Petrie JR, Connell JM. Insulin and hypertension. J Hypertens 1994; 12 : 633-642.

39 Scherrer U, Randin D, Vollenweider P. Nitric oxide release accounts for insulin's vascular effects in human. J Clin Invest 1994; 94: 2511-2515. 